\title{
Rhinology', and Otology.
}

nitrous oxide is first given, followed ly ether; while during the operation, if it in nevessary, the anesthesia i, hept up with chloroform given cautiourly from a piece of lint. In young children chloroform in given from the first, and if taken well is continued throughout the operation. If, on the other hand, there is any reason from the feeble condition of the patient to suspect faintnes, the chloroform in replaced by ether as soon as the patient becrmes semi-conscious.

Regarding the position of the patient, it should be one which is conducive in the safe administration of the and'sthetic and one which will have no tenlency to atrgravate shock. It must be a position alow which will allow the operator free access to the pharyn and permit of the rapicl eicape of ldoocl, while at the same time it retardi the suction into the laryn of detached pieces of adenoid tissue. () the many positions employed the most alvantageous of all is with the patient upon his back, the head fully extended or hanging ower the eilge of the talle. This position (first called attention to hy Mr. Mitchell I3anks) places the patient in the safent position for the administration of any anv'shetic, and is one which is directly antagonistic to the production of shock. It is also the most stable porition. In addition, with the head extended and the mouth open, reppiration is most eavily performed. It also gives the operatur a grood view of, and free arcens to, the

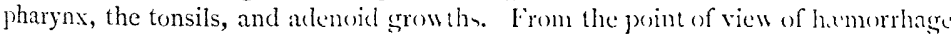
the position is likewise most allvantageou. With the head fully cxtented, the nostrils and the upper incisor tecth are placed on a lower level than the aperture of the larynx. Hence blood gravitates at once to these most depentent joints. An objection has been urged agrainst this position that the congestion from the dependent position increase's the hamorrhagre. Although this may 10 some extent he true, the advantages of the position greatly outweigh this disadvantage, while it must also be remembered that the amount of hemorrhage depends to a grent extent upon the particular method of operating.

IV. Milligan.

Pissot, C. - On Naso-Pharyngcal Irrigation-its Indiations. Thi'se de: Paris, 1895 .

Notes on the indications of maso-pharyngeal irrigation; in chronic purulem rhinitis, sinusitis, and as a prophlylactic in eruptive ferers (mensles, scarlatina, typhoid fever, etc.). A. Carta:

\section{LARYNX AND TRACHEA.}

Rethi (Wien). - Some Rare Lary'ngeal and Pharyngeal Affictions following Influenza. "Wiener Klin. Woch.," I894, No. 48.

1. A patiext, fifty-eight years old, accuired influenza. A few days after he contracted pain in the neck and hoarsenes. The examination showed the evistence of herpes of the soft palate, and a median perition of the right wocal cord (paralysis of the right recurrent). The herpen wa - hortly curced, and the paraly, in disappeared in albout three weeks.

2. A patient, forty-five yeurs old, sufferer from infuenza and febrile tracheobronchitis. The laryngoscope shewed a median ponition of the left vecal corr. In this case also the condition mut be regrarled an recurrent paralysis.

3. A patient, eighteen years old, with febrile influen/a and largngitis, with cough, on the fifth clay of the disease presenterl an swelling oser the thyreisl region, combined with redness and swelling of the laryngeal mucons membrane. The swelling and hyper-sensibility of the threat and nech pervisted for cight weeks, and then slowly disappeared. 
4. A patient, thirty-three years old, attacked with influenza, presented six days afterwards a tumour the size of a nut over the laryngeal surface of the epiglottis. The patient did not allow any operation, but twelve days later he discharged a great deal of pus on coughing. The laryngoscope now showed an ulcer in the place of the tumour, which was cured in three weeks.

5. In one case the author observed a fibrinous pharyngitis complicating an influenza and followed by an erythema nodosum of the skin.

6. A patient, eleven years of age, had large adenoid vegetations of the nasopharynx which caused complete obstruction of the nose, and which it was intended to operate upon had not the patient been attacked with febrile influenza. When the influenza was cured the adenoid vegetations and their consequences, viz., obstruction of the nose and aprosexia, had disappeared. This disappearance of such growths in acute infectious diseases is very rare. More often an enlargement of the hypertrophied tissues is observed.

Wichacl.

Haring, N. C.-Nodes of the Vocal Cords. " The Med. Chron.," Feb., I\$95.

THE main symptoms complained of are undue fatigue in speaking, and loss of the singing voice, the high notes being the first to be lust. In almost all cases there is a history of excessive use of the voice, the occupation of the patients being school-teachers, singers, preachers, etc. Of twenty cases analyzed, fifteen occurred between the ages of eighteen and twenty-two. None were under eighteen, while the oldest was forty-four. Sixteen of the twenty patients were females. The writer regards the actual cause of the trouble to be mechanical injury to the cord, due to want of tone set up by fatigue. Regarding treatment, the first and main indication is vocal rest. If after one month's rest of the voice the tone of the vocal cords is not re-established, and the patient is unable, owing to the nature of his or her calling, to reduce the vocal strain, a change of occupation should be enjoined. Locally, chromic acid fused upon a probe, and applied to the nodes, will be found efficacious. During an intercurrent attack of catarrh, treatment should be stopped.

W. Milligian.

Virey.-Stridulous Laryngitis with Lasting Aphonia. "Journ. de Clin. et Thérap. Infants.," Feb. 21, 1895 .

THE title indicates the cases. No laryngoscopic examination was made. Spontaneous cure of the aphonia occurred some days after.

4. Cartaz.

Baumgarten (Pesth).-Etiology of Laryngeal Cancer. "Pester Med. Chir. Presse," I894, No. 24.

IN two cases the affection arose in persons who shouted and spoke very greatly, and in both it followed a chronic laryngeal catarrh. One of them was a gentleman, sixty-two years old, who was a member of many clubs where there was much toasting; the second, a man, seventy-six years old, who shouted very much. The author believes that there is a relation between the disease and the excessive use of the voice.

Michatl.

Berndl (Strelsund).--Removal of Foreign Bodies from the Larynx of a Child, one and three-quarter years of age. "Deutsche Zeitsch. fur Chir.," Band 39, Heft 5 and 6.

A Chiln, one and three-quarter years of age, who had swallowed a walnut, suddenly became dyspnoic with severe stridor and hoarseness. Tracheotomy was performed. Respiration became normal, but the canula could not be removed and the hoarseness remained. Ten days later, thyrotomy and removal of three pieces 
of walnut. Suture of the cricoid cartilage. Eight days later the canula was removed. Cure resulted with normal voice. In such young children a good result from these operations is very rarely obtained.

Michael.

Mendel.-Tubercular Laryngitis. " "Ann. de Méd.," Feb. I 5, I895.

Review. Nothing new.

A. Cartaz.

Variot.-Some Reflections on Laryngeal Tubage in Diphtheria. "Journ. de Clin. Infant., "Jan. 24, I 895.

THE author relates the various complications of this operation, and shows from some cases that tubage is dangerous in private practice, when it is impossible to ensure the presence of a medical attendant. The tube is frequently obstructed by pseudomembrane or suppuration, or easily rejected.

A. Cartaz.

Eymonnet, V.-Tracheotony in Adults-Technique and Indications. "Thèse de Paris, 1895.

Review of the principal methods of tracheotomy and its indications. Nothing new.

A. Cartaz.

Maunoury.-Laryngeal Extirpation. "Bull. Soc. de Chir., Paris," XX., p. $8_{59}$.

THE observation of a workman, aged fifty-eight, having difficulty of breathing and dysphagia for some months. Hoarseness and some irritation of the fauces had lasted ten years. Tracheotomy became necesssary for sudden suffocation.

At the laryngoscopical examination malignant tumour of the larynx was found. Anæsthesia, Trendelenburg's canula, and vertical laryngectomy made the diagnosis complete. The epithelioma invaded the two parts of the larynx. Total extirpation by Yerier's procecding was carried out (transverse superior and inferior sections). Cure resulted in three weeks.

A. Cartaz.

Péan.-Total Extirpation of the Larynx Superior Part of the Esophagues, and Inferior Part of the Pharynx. "Bull. Acad. de Méd., Paris," Jan. 22, I\$95.

THE case of a man, fifty years of age, with epithelioma of the larynx. No troulles of deglutition. He was operated upon on November 29th, under chloroform anasthesia. A vertical incision of the soft parts of the neck was made. Complete transverse section of the trachea and insertion of Trendelenburg's canula. Section of the thyroilcartilage; the larynx wasinvaded on both sides by cancerous infiltration. Extirpation of the larynx, with the hyoid bone, was performed. The disease was not confined to the larynx; the superior part of the cesophagus and inferior part of the pharynx were also degenerated. Excision of these parts with resection of the carotid artery after ligature was performed. The trachea was sutured to the external integument; the orifice of the osophagus was sutured behind, and an cescphageal tube left in situ. The histological examination confirmed the diagnosis of epithelioma. There was a successful result. After a month the cicatrization was complete, the osophageal aperture being situated two centimitres above the tracheal orifice.

The author has completed the operation by a prothetic apparatus, uniting the osophageal tube with the tracheal canula, permitting of easy feeding and the passage of inspired air by the pharynx and nasal fosse.

The author gives the statistical results of cases of laryngectomy with extirjation of parts of the oesophagus or pharynx. In thirty-seven cases, death has occurred twenty-three times in from one day to seven months-from pneumonia, ten ; relapse of cancerous disease, four ; collapse, fuur ; inanition, four ; secontary homorrhage, two; septicimia, one. A. Cartaz. 
Frankenberger (Prag). - On Artificial Tracheal Stenoses. "Allg. Wiener Med. Zeitung," I895, Nos. I, 3 and 5.

EXPERIMENTAL researches on animals.

Michael.

Colley (Marburg).-Resection of the Trachca. "Deutsche Zeitsch. fir Chir.," Band 40, IIeft I and 2.

RESECTION of the trachea was performed, in a case of stricture of the trachea in consequence of traumatism, with good results. The author then made experiments as to the hest method of resection, and concluded that it would be best to cut the cartilages in bayonet form, so that the resected part should consist of the posterior halves of three cartilages and the anterior halves of three other cartilages. By this proceeding cicatricial stricture is prevented.

Miichael.

Ewald (Wien).-Tracheal Compression from Struma and its Conscunemes.

"Vierteljahrschrift fur Gerichtliche Medicin," I894, Supplement.

A paper of the greatest interest. Many researches have shown that the thyroil gland is not separated from the trachea by a capsule, but that the hypertrophic colloid tissue of the thyroid gland always reached to the perichondrium of the trachea. This adhesion of the thyroid gland to the trachea is the principal cause of the compression of the trachea by struma. By this adhesion the vessels alout the trachea, and those of the trachea itself, are also compressed, and, therefore, catarrh by stagnation may easily arise. Single tumours circumscribed by the same connective capsule as the trachea can only increase in this capsule, and prorluce, therefore, the different forms of compression observed in such cases. This hypothesis also explains why often great stenoses are caused by rather small tumours; the peculiarity of sudden death by goitre also can be understood by this acthesion.

Michael.

Lautier.-Death occurring by Penetration into the Left Bronchus of a Tracheotomy Tuhe. "Bull. Soc. Scientif. de l'Ouest," III., 4, p. 223.

A MAN, sixty years old, was tracheotomized fifteen years previously for laryngeal stenosis. For many years the patient used bad tubes without pinion, and one day the tube slipped through the tracheal opening and occluded the respiratory tract. Unsuccessful attempts were made at extraction, and death resulted from asphyxia. At the post-mortem examination the tube was found fixed in the left bronchus.

A. Cartar.

\section{THYROID GLAND, NECK, \&G.}

Kocher (Bcm). - The Function of the Thyroid Gland with relation to the New Methods of Tratment of the diverse Forms of Goitre. "Correspll. fur Schweizer Aerzte," I895, No. I.

In twelve cases the author has used thyroid gland extract in cases of goitre. In five cases observed in the hospital and in five out-patient cases a definite influence of the treatment could be observed; the goitres decreased in a high degree, lut in no case disappeared. Nearly the same effect is obtained by the well-known iodine treatment. The experience of many years shows that nearly ninety per cent. of all cases can be improved by the use of iodine; only in ten per cent. does surgical treatment become necessary. The author, therefore, does not believe that the new treatment will have any great practical value in the treatment of gnitre. (Of much greater value is feeding with thyroid gland for treatment of cachexia strumi- 